\title{
La influencia de los Castigos del rey Sancho IV en el ideal femenino de Juan Manuel en El conde Lucanor: análisis del ejemplo XXVII*
}

\author{
Antonia CABOT GARRIDO \\ antonia.cabot@e-campus.uab.cat \\ Universitat Autònoma de Barcelona
}

Los Castigos del rey don Sancho IV, probablemente acabado de redactar entre 1292 y 1293 , representa el colofón de la literatura sapiencial del siglo XIII y el mejor exponente de la literatura e ideología políticas auspiciadas por Sancho IV ${ }^{1}$. De controvertida autoría, atribuida a uno o varios clérigos ${ }^{2}$, persigue una triple finalidad propagandística: legitimarse y legitimar a su hijo Fernando ante la falta de reconocimiento papal de su enlace con María de Molina; desdibujar la imagen forjada por la maldición de su padre ${ }^{3}$ y fortalecerse frente a la nobleza, que le ayudó

\footnotetext{
${ }^{1}$ Sobre la biografía y reinado de Sancho IV, vid. Mercedes Gaibrois, Historia del reinado de Sancho IV de Castilla, Madrid, Tipografía de la RABM, 1922 (tomo I) y 1928 (tomos II y III) y José Manuel Nieto Soria, Sancho IV (1284-1295), Palencia, La Olmeda, 1994. Para una introducción a la literatura y ambiente cultural del período, vid. Carlos Alvar y José María Lucía Megías (eds.), La literatura en la época de Sancho IV: Actas del Congreso Internacional «La literatura en la época de Sancho IV», Alcalá de Henares, Universidad de Alcalá, 1996 y Fernando Gómez Redondo, Historia de la prosa medieval castellana. La creación del discurso prosístico: el entramado cortesano, vol. I, Madrid, Cátedra, 1998, pp. 853-1204.

${ }^{2}$ Sobre la autoría, trascendencia y valores de la obra, vid. Hugo O. Bizzarri, «Reflexiones sobre la empresa cultural del rey don Sancho IV de Castilla», Anuario de estudios medievales, 31/1 (2001), pp. 429-433; Rafael Beltrán, «El valor del consejo en los Castigos e Documentos del rey don Sancho», en Carlos Alvar y José María Megías, La literatura en la época de Sancho IV, op. cit., pp. 107-120; Rosa María Lida de Malkiel, Estudios de literatura española y comparada, Eudeba, Buenos Aires, 1966, p. 93. Bizzarri sintetiza en su artículo las aportaciones sobre la autoría de Pascual de Gayangos, Paul Groussac, Arturo García de la Fuente, Agapito Rey y R. Weaver.

${ }^{3}$ «Alfonso X maldijo a su hijo don Sancho, que se sepa, tres veces, la primera en público el 8 de octubre de 1282, y luego en dos testamentos, escritos el 8 de noviembre de 1283 y el 10 de noviembre de 1284». María Cecilia Ruiz, Literatura y política: el Libro de los Estados y el Libro de las Armas de don Juan Manuel, Potomac (Maryland), Scripta Humanistica, 1989, p. 121; «le maldecimos, como a merecedor de la maldición paterna, reprovado de Dios, e digno de ser aborrecido, con justa razón, de los hombres. E le sujetamos en adelante a la maldición divina e humana. E como a hijo rebelde, inobediente e contumaz, ingrato e ingratíssimo, e por tanto degenerado, le desheredamos e privamos de qualquier derecho, que haya tenido a nuestros Regnos, sennorios, tierras, honores, e dignidades, o otra cualquier cosa que en alguna manera nos pertenezca, para que ni el, ni otro por el, ni ningún descendiente suyo pueda jamás sucedernos, en cosa alguna». «Sentencia de maldición y desheredamiento de Sancho», apud Antonio Ballesteros-Beretta, Alfonso X el Sabio [1963], Barcelona, El Albir, 1984, p. 997.
} 
a alzarse con el trono, pero que constituyó un permanente elemento de inestabilidad, y frente las pretensiones de los infantes de la Cerda, apoyadas por la Corona de Aragón.

María de Molina y el futuro Sancho IV contrajeron matrimonio en 1282. La boda, no concertada, materializó su sublevación contra Alfonso $\mathrm{X}$ a raíz de la cuestión sucesoria. Con ella, Sancho, además de romper sus esponsales con Guillerma de Bearne, se unía con la hija de uno de los principales oponentes de su padre 4 . El enlace no fue reconocido por Roma, no solo porque se consideraba que Sancho estaba ya casado, aunque no se había consumado la unión anterior, sino porque además resultaba incestuoso, ya que los contrayentes eran parientes consanguíneos en tercer grado y canónicos -María era la madrina de una de las hijas ilegítimas de Sancho-. Por ello, los futuros monarcas y las ciudades que los apoyaron fueron excomulgados ${ }^{5}$.

La nobleza, ante el descontento por la política fiscal y la obra legislativa de Alfonso X, apoyó las aspiraciones al trono de Sancho ${ }^{6}$. El infante Manuel, hermano predilecto y consejero de Alfonso X y padre

La maldición se repite en el primer testamento: «que sea maldicho de Dios, et de Santa María et de toda la corte celestial, et de nos». Salvador Martínez Santamaría, Alfonso X, el Sabio, Madrid, Polifemo Ediciones, 2003, apéndice, p. 611. Sobre el conflicto sucesorio, vid. Antonio Ballesteros-Beretta, Alfonso X el Sabio, op. cit.; Jerry R. Craddock, «Dynasty in Dispute: Alfonso X el Sabio and the Succession to the Throne of Castile and Leon in History and Legend», Viator, 17 (1986), pp. 197-219; Leonardo Funes, «La blasfemia del rey Sabio: itinerario narrativo de una leyenda (Primera parte)», Incipit, 13 (1993), pp. 51-70; Leonardo Funes, «La blasfemia del rey Sabio: itinerario narrativo de una leyenda (Segunda parte)», Incipit, 14 (1994), pp. 69-101; Leonardo Funes, «La leyenda de la blasfemia del Rey Sabio: revisión de su itinerario narrativo», e-Spania, 25 (2016). En línea. DOI: http://dx.doi.org/10.4000/espania.25873; George Martin, «Alphonse X maudit son fils», Atalaya, 5 (1994), pp. 153-178; Salvador Martínez Santamaría, Alfonso X, el Sabio, op. cit., y María Cecilia Ruiz, Literatura y politica, op. cit.

${ }^{4}$ María de Molina era hija del infante Alfonso de Molina, hermano de Fernando III y «one of the principal leaders of the rebellion against the Wise King», Richard P. Kinkade, «Violante de Aragón (1236?-1300?): An historical overview», Exemplaria Hispanica, 2 (1992-1993), p. 11. El matrimonio se celebró «without either papal dispensation or his father's blessing. Furhtermore, and we may supose with his mother's approval», ibid., p. 32.

${ }^{5}$ Sobre el enlace, vid. Alejandro Marcos Pous, «Los dos matrimonios de Sancho IV en Castilla», Cuaderno de trabajos de la Escuela Española de Arqueología e Historia en Roma, 8 (1956), pp. 7-108, p. 43. A pesar de que el clero castellano apoyó al infante, Roma se posicionó de parte de Alfonso X: «fue el clero el que, primero, ayudará a don Sancho a arrebatar el trono a su padre, $y$, después, se pondrá enteramente a su disposición para acabar con el concepto cultural alfonsí, dando un viraje radical al mismo con la instauración, bajo la regencia de doña María de Molina, de un nuevo modelo cultural que volverá a la visión religiosa de la cultura, según el canon del siglo anterior», Salvador Martínez Santamaría, Alfonso X, op. cit., p. 355. El rechazo de Roma a la rebelión fue contundente: «el papa Martín IV pronunciaba en Orvieto el 9 de agosto de 1283 su célebre sentencia a favor de Alfonso, condenando la rebelión de don Sancho como un acto de traición e imponiéndole la excomunión y declarando en entredicho el reino, hasta que el pueblo volviese a la obediencia del rey Alfonso», ibid., p. 520.

${ }^{6}$ Durante el reinado de Alfonso X, fueron frecuentes los levantamientos nobiliarios: «la nobleza recurrió a la revuelta y a la guerra para ampliar sus dominios y posesiones en el interior de los reinos, adquirir nuevas tierras en el exterior y forzar al rey a limitar la influencia de los juristas», José Luis Martín Rodríguez, Manual de Historia de España. 2. La historia medieval, 
de Juan Manuel, tuvo un papel determinante en el golpe de Estado ${ }^{7}$. Tras rebelarse y hacerse con el poder, Sancho fue desheredado y maldecido por su padre. La maldición le afectó profundamente - tal y como supuestamente le recordaría a Juan Manuel en su lecho de muerte-, condicionó su reputación y repercutió en la política, pensamiento y religiosidad de su reinado ${ }^{8}$.

Aunque había llegado al poder gracias al apoyo nobiliario, las luchas intestinas e intentos por fortalecerse de este estamento -con episodios como el asesinato de Lope Díaz de Haro en $1288^{9}$-, las constantes sublevaciones y las aspiraciones del infante Juan sobre el reino de León y el apoyo de Aragón y de parte de la nobleza a la causa de los infantes de la Cerda marcaron la política y obra cultural del reinado de Sancho IV. En este sentido, Germán Orduna y Gómez Redondo consideran que Sancho IV y María de Molina se apoyaron en el clero, concretamente en el círculo catedralicio de Toledo, encabezado por Gonzalo Pérez Gudiel, para crear un proyecto ideológico cultural, caracterizado y denominado molinismo por Gómez Redondo. El molinismo se iniciaría durante el reinado Sancho IV y continuaría, tras la prematura muerte del monarca, durante los reinados de Fernando IV y Alfonso $\mathrm{XI}^{10}$. Este sistema de

Madrid, Historia 16, 1993, p. 360. Vid. Mercedes Gaibrois, Sancho IV, op. cit., tomo I, p. 9 y José Manuel Nieto Soria, Sancho IV (1284-1295), op. cit., p. 44.

${ }^{7}$ Las palabras que, según la Crónica de Alfonso X, propiciaron que Sancho se hiciese con el poder fueron: «el árbol de los reyes non se pierde por postura, nin se desereda por y al que viene por natura. E si el mayor que viene del árbol fallesçe, deue fincar la rama de so él en somo. E tres cosas son que no son postura, ley nin rey nin reino. E cosa que sea fecha contra cualquiera de éstas, non vale nin deue ser tenida nin guardada», Crónica de Alfonso X, Manuel González Jiménez (ed.), Murcia, Real Academia Alfonso X el Sabio, 1998, cap. LXVII, pp. 190-191. Sobre el infante Manuel, vid. Richard P. Kinkade, Albores de una dinastía: la vida y los tiempos del infante Manuel de Castilla, Albacete, Instituto de Estudios Albacetenses «Don Juan Manuel», Excma. Diputación de Albacete (Serie I, Estudios, 245), 2019.

${ }^{8}$ «Ca bien cred que esta muerte que yo muero non es muerte de dolençia, mas es muerte que me dan mios pecados, et sennalada mente por la maldiçion que me dieron mio[s]s padre[s] por muchos mereçimientos que les yo mereci», Juan Manuel, Libro de las armas, José Manuel Blecua (ed.), Obras completas, tomo I, Madrid, Gredos, 1981, p. 137.

${ }^{9}$ Mercedes Gaibrois, Sancho IV, op. cit., tomo I, p. 191.

${ }^{10}$ Martínez Santamaría explica este cambio de paradigma cultural: «a la muerte de Alfonso $\mathrm{X}$ hubo, por influjo de doña María de Molina, esposa de Sancho IV, y de los altos cargos de la Iglesia, una reacción muy negativa a la empresa cultural alfonsí; llevándose a cabo un viraje radical hacia posiciones político-teológicas más tradicionales, que comportaban el abandono del concepto secular del gobierno y la monarquía alfonsíes», Alfonso X, op. cit, p. 141. Germán Orduna abordó la influencia de los clérigos de la diócesis toledana en «La élite intelectual de la escuela catedralicia de Toledo y la literatura en la época de Sancho IV», en La literatura en la época de Sancho IV, op. cit., pp. 53-62. Fernando Gómez Redondo ha definido, vinculándolo a la escuela catedralicia de Toledo, y caracterizado el molinismo en Historia de la prosa medieval castellana. La creación del discurso prosístico: el entramado cortesano, op. cit., vol. 1, pp. 856-863 y, entre otros, en «El molinismo: un sistema de pensamiento letrado (1284-1350)», en Antonia Martínez Pérez y Ana Luisa Baquero Escudero (coords.), Estudios de literatura medieval: 25 años de la Asociación Hispánica de Literatura Medieval, Murcia, Universidad de Murcia, 2012, pp. 45-81; ha caracterizado a Juan Manuel como escritor molinista, entre otros, en «Don Juan Manuel, autor molinista», en Margarita Freixas y Silvia Iriso 
pensamiento se habría sustentado en los principios morales de la ortodoxia cristiana, en el pensamiento tomista, en el rechazo del conocimiento empírico y en el regalismo, y habría trazado la imagen alfonsí de un rey vicario de Dios en la Tierra, intermediario entre la divinidad y el pueblo. La traducción del Libro del tesoro y la redacción del Lucidario, los Castigos, el Libro del caballero Zifar, Barlaan, La gran conquista de ultramar y la obra literaria de Juan Manuel, compuesta durante el reinado de Alfonso XI, constituirían sus testimonios literarios más representativos. Bizzarri y Funes, sin embargo, han matizado la unidad y continuidad de este movimiento cultural ${ }^{11}$ :

Lo curioso es la falta de indicios claros de la dirección de esa empresa cultural y, en el caso particular del «molinismo», que luego de muerto el rey no continuara con una labor más contundente, cuando, por ejemplo, las pretensiones de los Infantes de la Cerda o el problema de la dispensa papal continuaron y la reina doña María tuvo la indiscutible dirección del reino ${ }^{12}$.

Otra falla metodológica ha sido la de otorgar casi absoluta credibilidad al testimonio de los cronistas de fines del siglo XIII y principios del XIV en [...] los perfiles de los personajes regios. Pensemos en el caso del ensalzamiento de doña María de Molina por parte de Fernán Sánchez de Valladolid [...] La reconstrucción histórica moderna de la trayectoria de la reina sobre otras bases documentales ofrece un retrato menos brillante, con errores políticos graves y enormes dificultades para superar una debilidad política endémica durante el reinado de su hijo y la minoridad de su nieto. No podemos saber hasta qué punto tuvo impacto entre los castellanos del siglo XIV la fantástica construcción cronística de una figura paradigmática en lo político y de una estatura moral y religiosa sobresaliente. Lo que sí sabemos con certeza es que esa construcción ideológica ha tenido completa eficacia entre la crítica (y los historiadores) de la era contemporánea ${ }^{13}$.

No es mi objetivo analizar posibles enfoques de estudio de este período; en este artículo me referiré a él como molinismo porque Juan Manuel construye El conde Lucanor a partir de premisas ideológicas análogas a las de los Castigos. En esta obra, Sancho se erige como modelo de soberano y de comportamiento vital, y rodea su llegada al trono

Ariz (coords.), Actas del VIII Congreso de la Asociación Hispánica de Literatura Medieval, vol. I, Santander, Asociación Hispánica de Literatura Medieval, 2000, pp. 291-301; y en «Don Juan Manuel, Trastámara», Cahiers de linguistique et de civilisation hispaniques médiévales, 25 (2002), pp. 163-181.

${ }^{11}$ Vid. Leonardo Funes ha rebatido la concepción molinista de Gómez Redondo en «Historiografía nobiliaria castellana del período post-alfonsí: un objeto de debate», La corónica: A Journal of Medieval Hispanic Languages, Literatures and Cultures, 43 (2014), pp. 21-55.

${ }^{12}$ Hugo O. Bizzarri, «Reflexiones sobre la empresa cultural», op. cit., pp. 432-433.

${ }^{13}$ Leonardo Funes, «Historiografía nobiliaria castellana», op. cit., pp. 80 y 81 . 
con un aura de mesianismo. Este carácter modélico aspira a proyectarse en su hijo para legitimarlo y liberarlo del carácter congénito de las maldiciones en la Edad Media ${ }^{14}$.

Herederos de los principios de la ética neoaristotélica, condensada por Brunetto Latini, y tomista, los códigos éticos de Sancho IV, plasmado en los Castigos, y manuelino, sintetizado en El conde Lucanor, advierten de los peccati linguae -la verdad, la poridad, la lisonja y la mentira- y se basan en la mesura, prudencia, contención, lealtad y vergüenza, virtud capital de su código ético, cifrada en la reputación social y orgullo individual que merece el linaje y acciones personales ${ }^{15}$. En los Castigos se caracteriza la así:

Vergüença es freno de toda maldat. E el que vergüença ha de sý mesmo conuiene que la aya de Dios $e$ de todos los otros omes quel veen $e$ lo oyen. El mal omne non puede seer acabado en toda maldat a menos de perder de sí vergüença, e, desque la ha perdida, non se siente de mal que faga. E desque la vergüença pierde, tiene que faziendo mal biue a su sabor, $e$ es vida astrosa $e$ menguada $e$ lixosa, $e$ tiénela por buena $e$ por acabada. E tanto le da que ande desnudo commo si andudiese bien vestido. $E$ tantol da que coma mal commo si comiese bien $e$ non se siente de ninguna cosa. ¿Qué te diré más? Torrnal de estado de omne a seer bestia ${ }^{16}$.

La vergüença raygada en $e$ coraçón del omne bueno $e$ de la buena mujer guarda el themor de Dios $e$ dal conosçençia contra Él. La vergüença desuía los malos fechos $e$ da carrera por que se fagan los buenos. La vergüença faze conosçer a omne el linaje onde viene $e$ que tome vergüença de su linaje $e$ de sí mesmo $e$ de los que han de venir dél. Ca por fecho que faga omne contra su generación de vergüença él lo echará en vergüença. Por eso fue fecha la cauallería de los fijosdalgo, por que ouiesen vergüença. Lo primero del linaje onde viene. Lo segundo de sí mesmo. Lo terçero de aquellos que han de venir déllos. $E$ guardando estas otras vergüenças fazen los fijosdalgo bien ${ }^{17}$.

${ }^{14}$ «Según la mentalidad medieval, la maldición y la bendición son fuerzas inelectables que pasan de generación en generación cumpliendo su dictamen», María Cecilia Ruiz, Literatura y politica, op. cit., p. 120.

${ }^{15}$ Sobre el concepto de vergüenza, vid. Juan Manuel Cacho Blecua, «La vergüenza en el discurso del poder laico desde Alfonso X a Don Juan Manuel», en José Manuel Lucía Megías (ed.), Actas del VI Congreso de la Asociación Hispánica de Literatura Medieval, Alcalá de Henares, Universidad de Alcalá, I, 1997, pp. 392-411; Id., «Vergüenza, sabiduría y pecado en la literatura medieval castellana (del Bonium a don Juan Manuel)», Príncipe de Viana, 61 (2000), pp. 75-102; y Antonio Carreño, «La vergüenza como constante social y narrativa en don Juan Manuel: el "Ejemplo L" de El conde Lucanor», Thesaurus: Boletín del Instituto Caro y Cuervo, 32/1 (1977), pp. 54-74.

${ }^{16}$ Castigos del rey don Sancho IV, Hugo O. Bizzarri (ed.), Madrid, Iberoamericana, 2001, cap. VI, p. 102.

${ }^{17}$ Ibid., p. 105. 
En el ejemplo L de El conde Lucanor, Juan Manuel pone en boca de la dueña protagonista los valores de este principio ético rector molinista:

la mejor cosa que omne puede aver en sí, et que es madre et cabeça de todas las bondades, dígovos que esta es la vergüenza. Ca por vergüença suffre omne la muerte, que es la más grave cosa que puede seer, et por vergüença dexa omne de fazer todas las cosas que non le parescen bien, por grand voluntat que aya de las fazer. Et assí, en la vergüença han comienço et cabo todas las bondades, et la vergüença es partimiento de todos los malos fechos ${ }^{18}$.

Con el término molinismo Gómez Redondo destaca el protagonismo de María de Molina en la configuración e impulso de este proyecto cultural e ideológico. Según Gómez Redondo, la implicación de la reina explica que en los Castigos no solo se proponga un modelo vital masculino, sino que también se perfile un modelo femenino, inspirado en la reina, ajustado a la ortodoxia cristiana, influido por el tomismo y el ideario feudal y cuya ética se rige también por la vergüenza:

Tal es la buena muger en que Dios pone vergüença grande $e$ buena commo aquella que está vestida de pannos de oro $e$ de aljófar $e$ de piedras preçiosas. E tal es la que non ha vergüença commo aquella que está toda desnuda. Pues para mientes cómmo paresçe la vna o la otra ${ }^{19}$.

Dyers también cree que «el interés en el papel de la mujer se debe a una realidad y a una preocupación personal y política del mismo Sancho $\mathrm{IV}$, que se refleja en el texto $\rangle^{20}$. En cualquier caso, inspirado o no por la reina, en la obra, apartándose de la exacerbada misoginia de las obras sapienciales de influencia oriental, se muestra el interés del rey por perfilar un ideal de mujer cristiana con componentes positivos, cuya moral y cualidades humanas se relacionan con la Virgen María, como bondadosa madre y esposa asexuada dotada de cierto entendimiento, en contraposición a Eva, como inductora del pecado original -considerado desde su dimensión sexual- y causante de la expulsión del Paraíso. Por ello, para trazar un esbozo de las cualidades en potencia de la mujer, se recupera la imagen de Eva antes del pecado edénico y se dibuja un modelo

${ }^{18}$ Juan Manuel, El conde Lucanor, Guillermo Serés (ed.), estudio preliminar de Germán Orduna, Barcelona, Crítica, 1994, p. 211. Ya había expuesto el concepto en el Libro del cavallero et del escudero, Obras completas, tomo I, cap. XIX, p. 49.

${ }^{19}$ Castigos, Bizzarri (ed.), ed. cit., cap. VI, p. 105

${ }^{20}$ Nancy J. Dyer, «El decoro femenino en Castigos e documentos del rey don Sancho $I V »$, en L.T. Valdivieso y Jorge Valdivieso (eds.), Studia Hispanica Medievalia. II Jornadas de Literatura Medieval Española, Buenos Aires, Universidad Católica Argentina, 1987, pp. 21-30, p. 22. 
femenino seglar, cuyas características morales son la lealtad, obediencia, sumisión, laboriosidad y buen juicio, siempre inferior al varón ${ }^{21}$ :

E Adam, nuestro padre, quando vio a Eua çerca sí que Dios criara $e$ fiziera de la costilla que dél sacara del su costado, dixo estas palabras profetizando lo que después auíe de venir: Tú serás llamada varona por que saliste de la costilla del varón $e$ serás mi conpannera ${ }^{22}$.

la muger, fecha por Nuestro Sennor Dios, era mucho buena [...] Dios la crió doctada de bienes de natura $e$ de fortuna $e$ de graçia. E primera mente de bienes de natura, ca era sabia non tanto commo Adam. Ca dize Sant Pablo que Adam jamás non fue engannado nin creyó lo que la syerpe dixo a Eua. E aquesto por tal commo auía menos seso, después era dotada de los dones que pertenesçen al ordenamiento natural, así commo buena voluntat, buenas inclinaçiones, claro entendimiento, buena industria, buena conçiençia, franco arbitrio, fermosura de cuerpo $e$ fortaleza conuenible, sabidoría conplida en todo lo que es menester en muger acabada ${ }^{23}$.

Desde la visión de Castigos, Adán también fue responsable de la expulsión del Paraíso por amar y desear más a la mujer que a Dios y por dejarse manipular por un ser inferior: «amó más consentir $e$ satisfazer a la muger que a Dios, por tanto quiso Dios que truxiese grand parte de sus cargos» ${ }^{24}$; de lo que se infiere que el varón siempre ha de someter a su compañera para no resultar perjudicado: «si el omne da sennoría a la muger sobre sý mesmo, que ella le será todos tienpos contraria» ${ }^{25}$.

Siguiendo los principios de la ortodoxia cristiana y de la doctrina tomista, se ensalza la virginidad y se considera la castidad el mejor es$\operatorname{tado}^{26}$, pero se considera que el lazo natural que une y somete a la mujer, creada como soporte y compañera ${ }^{27}$, al hombre es el matrimonio, que canaliza el apetito sexual ${ }^{28}$ y contribuye a la educación de la prole.

${ }^{21}$ Esta concepción también aparece en el Lucidario, P. Kinkade (ed.), Madrid, Gredos, 1968, cap. XIX, pp. 120-123.

${ }^{22}$ Castigos, Bizzarri (ed.), ed. cit., cap. XX, p. 197.

${ }^{23}$ Vid. Castigos, Bizzarri (ed.), ed. cit., Prólogo, pp. 71-72.

${ }^{24}$ Ibid., p. 73.

${ }^{25} \mathrm{Id}$.

${ }^{26}$ Vid. ibid., cap. XIX, pp. 189-195, cap. XXI, pp. 200-201, у cap. XXXVII, pp. 270-276.

${ }^{27}$ Tomás de Aquino considera que: «por naturaleza, la mujer es inferior al hombre en dignidad y en poder», Suma de Teología I. Parte I, Madrid, BAC, 2001, q. 92, art. 1, obj., p. 823 (en adelante $S T, \mathrm{I}$ ); por ello se somete a él en beneficio propio, ya que «la misma naturaleza dio al hombre más discernimiento.»ST, I, q. 92, art. 1, r. obj., p. 823. La existencia de la mujer se justifica por su contribución a la generación: «Fue necesaria la creación de la mujer, como dice la Escritura, para ayudar al varón no en alguna obra cualquiera, como sostuvieron algunos, ya que para otras obras podían prestarle mejor ayuda los otros hombres, sino para ayudarle en la generación.» $S T$, I, q. 92, art. 1, sol., p. 823.

${ }^{28}$ Vid. ibid., cap. VI, p. 102. 
Mediante él, la mujer auxilia y se somete a los designios de su esposo, pues se considera que lo inferior siempre debe subordinarse a lo superior ${ }^{29}$ :

La sesta buena andança te dará Dios en te casar con buen muger conplida de toda bondat, de la qual te dará Dios fijos e fijas de que ayas generaçión $e$ con que tomes plazer. E esta muger que sea tal que el tu coraçón esté bien seguro $e$ firme en la su bondat $e$ sin themor $e$ seyendo ella sin maldat, $e$ por la qual seyendo tú casado con ella sea a honrra de ti $e$ ayas por ella riquezas $e$ todo bien $e$ sea el casamiento e egualeza de ti lo más que se pueda fazer ${ }^{30}$.

El matrimonio se considera un vínculo indisoluble en que es incuestionable la fidelidad femenina. Dada la naturaleza de la mujer, debe huir del ocio, pues la conduce a la lujuria: «muger ocçiosa es saco de luxuria, grande parlera, corrubçión de muchos sin toda virtud, lazo de muchos mesquinos, confusión de su marido, vergüença de sus fijos, $e$ destruyçión de su casa» ${ }^{31}$. En el caso masculino, aunque se condena la infidelidad porque afecta a la honra de la esposa: «Desmesura es $e$ mal estança desonrrar la muger por la culpa del marido ${ }^{32}$, se incide especialmente en «non fazer pesar a Dios en pecados de forniçios» ${ }^{33}$ con mujeres vírgenes, monjas, infieles o casadas, es decir, en no tener relaciones con mujeres que pueden ser deshonradas o deshonrar ${ }^{34}$.

La relación emocional entre ambos cónyuges es considerada uno de los tipos de amor verdadero -recto en cuanto a su intención-, junto con el amor a Dios, al señor, a los amigos y a los semejantes, que mueve al hombre: "Amor verdadero mantiene en buena vida al marido con su muger $\rangle^{35}$. Su vínculo se basa en el afecto, la lealtad y ayuda mutua, asumiendo cada uno sus respectivas obligaciones; la mujer, las domésticas; el varón, las intelectuales y sociales:

${ }^{29} S T$, I, q. 92, art. 1, obj., y $S T$, I, q. 92, art. 1, r. obj.

${ }^{30}$ Castigos, ed. cit., cap. XLIII, p. 299. No es casual que sea la sexta fortuna. Alfonso X había trazado un sistema simbólico estructural en sus obras legislativas a partir del siete, pues ese era el número de letras de su nombre. Sancho lo asimilará a las seis letras del suyo. Vid. Fernando Gómez Redondo, Historia de la prosa medieval castellana, op . cit., p. 945.

${ }^{31}$ Ibid., cap. VI, p. 103.

${ }^{32}$ Ibid., cap. XIIII, p. 163.

${ }^{33}$ Ibid., cap. XIX, p. 189. V. Ibid., cap. XXXVII, p. 274.

${ }^{34}$ Vid. Ibid., cap. XIX, p. 189. Aunque aparecen referencias a las prostitutas, denominadas malas mugeres, en los capítulos VI y XXVIII, no se considera la posibilidad de que el futuro Fernando IV, implícitamente dotado de mayor perfección moral que sus súbditos, se degrade pecando con ellas. Alfonso X ya había prohibido la relación con mujeres viles, en Alfonso X el Sabio, Las Siete Partidas, Madrid, Real Academia de Historia, 1807, Partida II, título V, ley 3, pp. 26-27. También en los Castigos aparece la referencia de respetar a las viudas castas, vid. cap. XXXVII, p. 274.

${ }^{35}$ Castigos, Bizzarri (ed.), ed. cit., cap. XXV, p. 263. 
E por ésta dexarán los omnes [que] de aquí adelante verrnán los padres $e$ las madres e los parientes $e$ serán dos ayuntados de so vno. Otrosí dixo el profeta Dauid: La tu muger será commo buena çepa de vid abondada de todo bien en los lugares que la ouiéredes menester en la tu casa ${ }^{36}$.

Ca el día que el marido e la muger casan en la yglesia estando en la misa los ynojos fincados ántel altar, les ponen a amos a dos vn panno a las cuestas. El nouio tiene la cabeça descubierta $e$ la muger cúbrenle la cabeça con él en semejança que de allí adelante deue ella seer sobgeta del marido $e$ obedesçerle en todo $e$ non le fazer pesar. E por eso mandan los derechos que nuncan maten la muger por ninguna cosa que encubra a su marido ${ }^{37}$.

Juan Manuel, con el afán de preservar el orden establecido, en que el matrimonio organiza la vida doméstica, traslada en El conde Lucanor parcialmente el ideal de virtudes femeninas molinistas. De entrada, la diferencia más significativa es la falta de referencias a la maternidad, más allá de las alusiones anecdóticas de doña Truhana en el ejemplo VII, de la ambigua relación de la mujer del mercader con su hijo en el ejemplo XXXVI o de las pinceladas fisiológicas a la concepción y gestación presentes en el «Libro de la doctrina», fruto de la influencia del pensamiento tomista, que minimizaba la relevancia de la mujer en la procreación y su vínculo filial ${ }^{38}$.

El más derecho amor que en $e l$ mundo ha $e$ el más verdadero sí es del padre al fijo por las cosas que te yo agora diré. El padre quanto en el mundo ha $e$ gana $e$ puede ganar todo lo quiere dexar al su fijo. Otrosí el padre ante querríe veer la su muerte que la de su fijo, e él sienpre cobdiçia que Dios mengue en los sus días de la su vida $e$ cresca en la de su fijo, e ante querríe mal para sí que para su fijo. Otrosí fallamos en el libro que ha nonbre Génesis que quando fue el grand diluuio del agua en el tienpo de Noé, que los padres fuyen con los fijos a las montannas muy altas, $e$ alçáuanlos sobre sus cabeças con las manos, $e$ ante queríen ellos morir que non ver morir a sus fijos. E nunca los fijos murieron fasta que los padres eran estragados $e$ afogados teniéndolos sobre sus cabeças. E de las madres non contesçíe así. E fallamos que ellas subíen de pies sobre ellos, e primero queríen que muriesen sus fijos que ellas cuydando escapar por ello ${ }^{39}$.

\footnotetext{
${ }^{36}$ Ibid., cap. XX, p. 197.

${ }^{37}$ Ibid., cap. XX, p. 199.

${ }^{38}$ La idea se aprecia en $S T$, I, q. 92, a. 1, sol., y se repite, entre otros, en: «La potencia generativa en la hembra es imperfecta con relación a la que existe en el macho. Y por eso, así como en las artes la inferior dispone la materia, y la superior hace aparecer la forma, como se dice, en el libro II Phys., de modo semejante la virtud generativa de la hembra prepara la manera, y la virtud activa del macho da forma a la materia preparada», Tomás de Aquino, Suma de Teología V. Parte III e indices, Madrid, BAC, 1996, q. 32, a. 4, ad. 2, p. 299.

${ }^{39}$ Castigos, Bizzarri (ed.), ed. cit., cap. V, p. 97.
} 
El fijo es fecho de la simiente del padre, e por eso le ama de tan grand amor su padre. Ca es carne de la su carne $e$ huessos de los sus huessos. De la madre non contesçe así, ca el fijo non es fecho de la simiente de la madre, commo quier que bien es verdat que alguna parte ha délla, mas todo lo más es del padre ${ }^{40}$.

El influjo de este ideal de mujer leal se aprecia especialmente en los ejemplos XXVII y L, pero también en el XXV y XXXVI. Por cuestiones de espacio, me centraré en el XXVII. En él, con tintes humorísticos, Juan Manuel expone en boca de Patronio su concepción de la perfecta casada obviando los valores religiosos subyacentes en los Castigos y el concepto de vergüenza que aparece en el apólogo L. En la concepción del magnate, la sumisión y el buen entendimiento femenino, que no implica poseer sentido crítico, sino refrendar, apoyar y auxiliar los juicios del marido, son indispensables para una buena relación conyugal ${ }^{41}$.

Lucanor explica a Patronio la diferente relación de sus hermanos con sus esposas. Uno depende tanto de su mujer que es incapaz de separarse ella y siempre actúa según su voluntad (idea también presente en el ejemplo XXX), mientras que el otro aborrece a la suya y la evita. Para Patronio, ambos se equivocan porque: «ca el uno nin el otro non devían mostrar tan grand amor nin tan grand desamor commo muestran a aquellas dueñas con qui ellos son casados $\rangle^{42}$.

A pesar de que el conde ha planteado dos posturas masculinas extremas en las relaciones matrimoniales (el excesivo apego y dependencia y el aborrecimiento) y Patronio ha respondido proponiendo una relación conyugal mesurada, el ayo ilustra su consejo con dos ejemplos que no muestran directamente este modelo de mesura matrimonial, sino que definen, por contraposición, el paradigma femenino que lo posibilita. Aunque el tema principal del apólogo doble es la relevancia de conocer y saber escoger a la futura esposa, a la luz del desenlace del segundo ejemplo se hace evidente que Juan Manuel considera que la responsabilidad de alcanzar una vida conyugal pacífica depende de la capacidad del marido de someter a su esposa durante los primeros días de convivencia; si no lo hace, deberá conformarse con la situación:

${ }^{40}$ Ibid., p. 98.

${ }^{41}$ Para Juan Manuel: «la razón es la parte del espíritu humano que permite aprehender las más altas verdades y que diferencia al hombre del animal, y el entendimiento, que varía de hombre a hombre, es una cierta madurez intelectual que permite interpretar el mundo de los fenómenos». Luciana De Stefano, «Don Juan Manuel y el pensamiento medieval», en Don Juan Manuel, VII Centenario, Murcia, Academia Alfonso X el Sabio/Universidad de Murcia, 1982, pp. 337-351, p. 341.

42 Juan Manuel, El conde Lucanor, Serés, (ed.), ed. cit., p. 116. En los Castigos ya se advertía de que: «Tres cosas son que fazen errar al omne por sabidor $e$ por entendido que sea sy non se guardare déllas. La primera grand amor de muger. La segunda beudez de vyno. La tercera beudez de sanna. E el vino $e$ las mugeres fazen errar al omne sabidor», Castigos, Bizzarri (ed.), ed. cit., cap. I, p. 85. 
pues al comienço non pudo o non sopo poner ý consejo, non ay sinon pasar por su ventura como dios gelo quisiere endereçar. Pero sabed que para lo uno e para lo ál cunple mucho que del primer día que el omne casa deve dar a entender a su muger que él es señor e que le faga entender la vida que ha de pasar ${ }^{43}$.

El escritor, de nuevo con toques humorísticos ${ }^{44}$ y valiéndose de la técnica hiperbólica, reiterará la idea en el ejemplo XXXV, en que un muchacho pobre se casa con una mujer fuerte y brava, y la somete durante su noche de bodas coaccionándola mediante el ejercicio de la violencia física indirecta:

Et aquel día en adelante, fue aquella muger muy bien mandada et ovieron muy buena vida.

Et dende a pocos días, su suegro quiso fazer assí commo fiziera su yerno, et por aquella manera mató un gallo; et díxole su muger:

- A la fe, don fulán, tarde vos acordastes, ca ya non vos valdría nada si matássades cient cavallos; que ante lo oviérades a començar, ca bien nos conoscemos ${ }^{45}$.

El ayo empieza planteando en el primer ejemplo un arquetipo femenino negativo, cuyo dramático final acentúa su rechazo. En él, el emperador Fradrique se compromete sin conocer el carácter irascible de su futura esposa, de quien, despersonalizándola, no se menciona el nombre. Esta intencionada caracterización de los personajes introduce el punto de vista narrativo y social del ejemplo: mientras el antropónimo del emperador lo presenta como un ser individualizado, y remite quizá a un poderoso referente histórico ${ }^{46}$, se despersonaliza a su mujer al designarla de modo genérico y, siguiendo el tópico alfonsí presente en los Castigos de la nobleza de obras, se la caracteriza negativamente porque su «muy alta sangre» no se corresponde con sus «maneras»o comportamiento $^{47}$.

${ }^{43}$ Ibid., pp. 126-127.

${ }^{44}$ En ambos ejemplos se utiliza el humor y la sátira como herramienta ideológica para banalizar y subyugar la figura femenina.

${ }^{45}$ Ibid., p. 152. Mediante los adjetivos mandada y buena se hace patente que la armonía conyugal depende de la sumisión femenina.

${ }^{46}$ Podría ser Federico I Barbarroja, duque de Suabia (1150-1190) o Federico II (1197-250), ambos emparentados con Juan Manuel.

${ }^{47}$ «Semejante leemos de Santa Elisabed, fija del rey de Vngría [noble en linaje e mucho más noble en fee e en religión. Ca el su linaje tan noble ennoblesçiolo ella mucho más por enxienplos, e alunbrose por milagros, e apostolo por graçia de santidad, la qual Dios fazedor de todas las cosas marauillosa mente enxalsó sobre las obras del mundo», Castigos, Bizzarri (ed.), ed. cit., cap. VI, p. 105. El tópico alfonsí de la nobleza de obras se desarrolla en Las Siete Partidas, ed. cit., Partida II, título XXI, ley II, p. 213. 
Además de la familiaridad que se establece con los lectores al recurrir a personajes históricos cercanos, el hecho de que el protagonista sea un emperador acentúa los peligros de casarse con una mujer insumisa, que pone en peligro los asuntos públicos, de manera que se justifica la medida que finalmente adoptará para atajar sus problemas conyugales.

La noble - «de muy alta sangre»- y honesta - «buena dueña et muy guardada de su cuerpo» ${ }^{48}$ - emperatriz, una vez casados «començó a seer la más brava et la más fuerte et la más revessada cosa del mundo» ${ }^{49}$. Como cualidades asociadas a la masculinidad, el genio, la fortaleza, la determinación y el criterio propio son para una mujer tachas morales. La emperatriz no obedece y contradice sistemáticamente a su marido: «todas las cosas del mundo en que el emperador tomava placer, en todas dava ella a entender que tomava pesar; et de todo lo que el emperador fazía, de todo fazía ella el contrario sienpre» ${ }^{50}$. Esta insumisión, asimilada a una deslealtad análoga a la de un vasallo ${ }^{51}$, se presenta como la consecuencia de su carácter inmaduro, caprichoso, egoísta, voluble, desleal, desconfiado e irascible. No es la única mujer voluble en el ejemplario: Juan Manuel aborda el excesivo apego a una esposa caprichosa en el ejemplo XXX: «El rey Abenabet era casado con Ramayquía et amávala más que cosa del mundo. Et ella era muy buena muger et los moros han della muchos buenos exienplos. Pero avía una manera que non era muy buena; esto era que a las vezes tomava algunos antojos a su voluntad $\aleph^{52}$.

El lector conoce el carácter de la emperatriz, pero no el del emperador. No se consideran las posibles motivaciones de su rechazo hacia él porque en el férreo esquema jerárquico social medieval, los relatos y puntos de vista narrativos se configuran desde las posiciones de poder, en que la perspectiva femenina no existe. Es simplemente una rebelde sin causa. Por ello se caricaturizan e infantilizan sus reacciones, consideradas arbitrarias y antinaturales, ya que subvierten el orden social establecido: «Assí que si el emperador quería comer, ella dizía que quería ayunar; et si el emperador quería dormir, queriése ella levantar; et si el emperador querié bien alguno, luego ella lo desamava» ${ }^{53}$. Se presupone que el carácter y actuaciones de la emperatriz representan una alteración del orden natural, ocasionado por su propia debilidad y falta de entendimiento, que impide que rectifique su actitud a pesar de los continuados intentos del emperador por encauzarla. Para remarcar la contumacia de

${ }^{48}$ Ambas expresiones se encuentran en Juan Manuel, El conde Lucanor, Serés (ed.), ed. cit., p. 117.

${ }^{49} \mathrm{Id}$.

${ }^{50} \mathrm{Id}$.

${ }^{51}$ El molinismo también presentó la relación del hombre con Dios en términos de vasallaje: «ca Él [Dios] es tu Sennor $e$ tú eres su vasallo». Castigos, Bizzarri (ed.), ed. cit., cap. XIX, p. 189.

${ }^{52}$ Ibid, p. 134.

${ }^{53}$ Ibid., p. 117. 
la emperatriz y la buena intención de su cónyuge, el narrador precisa que «por ninguna guisa non la podía sacar desta entención por cosa que él nin otros le dixiessen, nin por ruegos nin por amenazas nin por buen talante nin por malo quel mostrasse $\rangle^{54}$. Como todos sus intentos han fracasado y el mal talante de su esposa afecta a los asuntos públicos, el emperador acude al pontífice, que le recuerda que el matrimonio es un sacramento indisoluble y le sugiere que aplique el principio del mal menor tomista para restablecer la tranquilidad en el reino ${ }^{55}$ :

Mas vio que segund la ley de los christianos non se podían partir et otrosý que en ninguna manera non podían vevir en uno por las malas maneras que la emperatriz avía, et sabía el Papa que esto era assí. Et desque otro cobro no podieron fallar, dixo el Papa al emperador que este fecho que lo acomendava él al entendimiento et a la sotileza del emperador, ca él non podía dar penitencia ante que el pecado fuesse fecho ${ }^{56}$.

Al regresar, realiza un último intento de corregirla que refuerza su magnanimidad frente a la obstinación de la emperatriz. Agotada su posibilidad de enmienda, su suerte está echada; el emperador le explica que se marcha a cazar y que le deja dos ungüentos: los restos del veneno que ha usado para untar las flechas, que la matarían si se los aplicase sobre la sarna o una herida, y otro medicinal, que el emperador se aplica delante los cortesanos, que trata la sarna. La emperatriz cree que su marido la engaña, y se unta con el veneno, a pesar de las advertencias de los cortesanos, que no logran, o no impiden, la acción. Su decisión es, pues, obra de su libre albedrío, que actúa coaccionado por su contumaz apetito irascible ${ }^{57}$, por lo que muere sabiendo que ella misma se ha provocado la muerte. Desde la ideología manuelina, su rebeldía, deslealtad, desconfianza, falta de entendimiento, carácter voluble, inquina y deslealtad contra su marido desencadenan su muerte. Como personaje peligroso para el orden social, su muerte culpable y ejemplificadora restablece el equilibrio.

La protagonista del otro ejemplo, en cambio, representa el buen entendimiento, la lealtad y sumisión marital molinistas, por lo que, a diferencia de la emperatriz, Patronio le concede una identidad. Desde su presentación posee una filiación y cuando se casa, es decir, cuando

${ }^{54} I d$.

${ }^{55}$ Cuando: «haya que elegir entre dos extremos sobre cada uno de los cuales amenaza el peligro, debe elegirse evidentemente aquel del que se siga un mal menor» Tomas de Aquino, La monarquía, Laureano Robles y Ángel Chueca (eds.), introducción de Eudaldo Forment, Madrid, Tecnos, 2012.

${ }^{56}$ El conde Lucanor, Serés (ed.), ed. cit., p. 117.

${ }^{57}$ Sobre el libre albedrío, vid. ST, I, q. 83. Sobre el apetito irascible, vid. Suma de Teología II. Parte I-II, Madrid, BAC, 1989, q. 23, a. 4, sol., y q. 29, a. 1, sol. 
empieza a desempeñar su función de género, se la dota de una identidad: «Et esta dueña avía nombre doña Vascuñana» ${ }^{58}$.

El ejemplo arranca cuando Álvar Háñez, sobrino del Cid y hombre de confianza de Alfonso VI, acude al conde Pero Ançúrez a pedir la mano de una de sus tres hijas. De nuevo, Juan Manuel recurre a personajes históricos, rodeados, además, de una aureola mítica por su relación con el Cid, para aproximar la narración a los lectores ${ }^{59}$. Siguiendo el esquema folclórico, presente también en el ejemplo XXIIII, en que se pone a prueba a tres hermanos, de los cuales siempre sale vencedor, por más astuto, el benjamín ${ }^{60}$, desea hablar con ellas para probarlas y escoger a la más apropiada ${ }^{61}$. Primero se entrevista con la primogénita y le explica que es viejo y que cuando bebe, por las heridas de guerra sufridas en la cabeza, se vuelve violento y, entre otras tachas no mencionadas, no controla sus esfínteres. La hipérbole en la caracterización grotesca de Álvar como viejo beodo e incontinente parece remarcar que ninguna mujer aceptaría un partido así6 ${ }^{62}$; sin embargo, el ayo aclara que: «Et destas cosas le dixo tantas, que toda mujer quel entendimiento non oviesse muy maduro se podría tener dél por non muy bien casada $\rangle^{63}$. Patronio incide en ello al relatar cómo comunica el rechazo a los condes; solo una mujer inteligente hubiese percibido el verdadero sentido de prueba de las palabras del pretendiente: «porque ella non fue de tan buen entendimiento commo le era mester, dixo a su padre et a su madre que tales cosas le dixiera don Álvar Háñez, que ante quería seer muerta que casar con él ${ }^{64}$. Lo mismo sucede con la hermana mediana, de la que no se aporta información, pues solo cumple una función narrativa de puente entre la primogénita y benjamina, quien, a diferencia de su hermana mayor, minimiza durante su entrevista todas las posibles tachas de Álvar. Le agradece y se siente honrada de que un noble de su relevancia haya querido casarse con ella, obviando la diferencia de edad entre ambos. Le asegura que no le dejará cometer dislates cuando beba, que no le dará motivos o sufrirá en silencio su violencia verbal y física

\footnotetext{
${ }^{58}$ Ibid., p. 121.

${ }^{59}$ Vid. Juan Manuel, El conde Lucanor, José Manuel Blecua (ed.), Madrid, Castalia, 1989, p. 163 , n. pie de p. 539.

${ }^{60}$ Además del origen folclórico, no se debe descartar la intención de incidir en las cualidades de los hermanos pequeños, ensalzando indirectamente, como en el ejemplo XXXIII, a su padre.

${ }^{61}$ Aunque es una situación ficcional y remite a una prueba de obediencia monacal existían antecedentes de selección presencial de esposa. Leonor de Aquitania, por ejemplo, viajó a Castilla para escoger esposa para el futuro Luis VIII entre sus nietas. Sobre la prueba monacal, vid. El conde Lucanor, Blecua (ed.), ed. cit., n. pie de p. 539, p. 163.

${ }^{62}$ Juan Manuel está reproduciendo dos lugares comunes del ideal ético de mesura molinista: la crítica a la embriaguez y a los arranques de cólera. V. n. pie de p. 42.

${ }^{63}$ El conde Lucanor, Serés (ed.), ed. cit., p. 120.

${ }^{64} \mathrm{Idem}$. La verdadera intención de las palabras, su valor como prueba o el engaño mediante el lenguaje son temas transversales de El conde Lucanor, que se manifiestan en este ejemplo a través de la caricatura de sí mismo con que se presenta a sus posibles esposas el pretendiente.
} 
si la agrede estando ebrio y le responde de forma adecuada a la falta de control de esfínteres y otras tachas que no se explicitan: «Et a todas las cosas que don Álvar Háñez le dixo, a todas le sopo tan bien responder, que don Álvar Háñez fue muy pagado» ${ }^{65}$.

Tras el matrimonio, su máximo objetivo es proteger los intereses de Álvar. Demuestra ser obediente y de buenas y discretas obras, fruto de su agudo entendimiento femenino, mediante el cual sus juicios se someten a los de su marido. No se pliega por conveniencia, sino porque se considera inferior y auxiliar a él, y cree que su marido siempre obra correctamente. Lo antepone a sí misma porque Dios la ha premiado amando a su esposo («porquel fizo Dios a ella tanto bien, que tanto amava a don Álvar Háñez» ${ }^{66}$ ) y guarda hacia él la lealtad de un vasallo hacia su señor porque considera que ha de plegarse al varón, criatura de mayor perfección. Para Juan Manuel, la sumisión de Vascuñana es fruto de su razón.

Su lealtad le vale la confianza de su marido, que la convierte en su consejera. El sobrino de Álvar le recrimina a su tío el excesivo influjo de Vascuñana: «Et el sobrino díxol que non fallava tacha quel poner sinon que fazía mucho por su muger et la apoderava mucho en toda su fazienda $»^{67}$. Para demostrarle que su acusación es falsa, salen de viaje sin ella. Poco antes de que se les una, ven unas vacas, pero Álvar afirma y se enroca en que son yeguas: «Et de que el sobrino vio que don Álvar Háñez porfiava tanto sobredesto et que lo dizía a todo su seso, fincó mucho espantado et cuydó que don Álvar Háñez avía perdido el entendimiento ${ }^{68}$. Cuando llega Vascuñana, afirma y argumenta, enfrentándose al sorprendido sobrino, que son yeguas:

- Por Dios, cuñado, pésame mucho desto que dezides, et sabe Dios que quisiera que con mayor seso et con mayor pro nos viniéssedes agora de casa del rey, do tanto avedes morado, ca bien veedes vós que muy grand mengua de entendimiento et de vista es tener que las yeguas que son vacas.

Et començól a mostrar, tan bien por las colores commo por las faciones commo por otras cosas muchas, que eran yeguas, et non vacas, et que era verdat que don Álvar Háñez dizía, que en ninguna manera el entendimiento et la palabra de don Álvar Háñez que nunca podría errar. Et tanto le afirmó esto, que ya el cuñado et todos los otros començaron a dubdar que ellos erravan et que don Álvar Háñez dizia verdat: que las que ellos tenían por vacas, que eran yeguas ${ }^{69}$.

\footnotetext{
${ }^{65}$ Ibid., pp. 120-121.

${ }^{66}$ Ibid., p. 121.

${ }^{67}$ Ibid., p. 122.

${ }^{68}$ Idem.

${ }^{69}$ Ibid., p. 123.
} 
La situación se repite cuando Álvar afirma que unas yeguas son vacas. La confusión del sobrino aumenta aún más cuando Vascuñana corrobora y argumenta la absurda afirmación de su marido de que una corriente de agua va al revés: «Et el sobrino de don Álvar Háñez se tovo por perdido cuando esto le oyó, ca tovo que, assí commo errara en el conoscimiento de las vacas et de las yeguas, que assí errava agora en cuydar que aquel río vinía al revés de commo dizía don Álvar Háñez» ${ }^{70}$. Finalmente, Álvar desentraña el misterio a su sobrino; ha sido una prueba para demostrar la lealtad de su esposa:

Et desque Vascuñana llegó et os oyó que yo dizía que eran yeguas, bien cierto só que entendia que vós dizíades verdat; mas que fió ella tanto en el mío entendimiento que tien que por cosa del mundo non podría errar, tovo que vos et ella errávades en non lo conocer cómmo era. Et por ende dixo tantas razones et tan buenas, que fizo entender a vós et a cuantos allí estavan que lo que yo dizía era verdat. Et esso mismo fizo después en lo de las yeguas et del río ${ }^{71}$.

En sus conclusiones, el ayo remarca que el marido ni ha de aborrecer ni anteponer a su mujer a los asuntos mundanos, pero debe tratarla bien y serle fiel: «que non le faga pesar nin enojo, e señaladamente en ninguna cosa en que pueda aver pecado, ca desto vienen muchos danios $\gg^{72}$.

Aunque Juan Manuel asimila el modelo femenino de los Castigos en cuanto a la capacidad y limitación del entendimiento, la realización vital y social mediante el matrimonio, el papel de activa y sumisa auxiliar del marido y la relevancia de la lealtad, la elusión de la maternidad, su función social primordial en la época, y la caracterización humorística estereotipada de las mujeres como soñadoras, iracundas, volubles o medrosas desdibuja y deshumaniza a la mujer en $C L$. Si los Castigos la presentaban como una hacendosa y limitadamente inteligente sumisa esposa cristiana y como una bondadosa madre asexuada y constataban el nexo emocional entre los esposos y la suerte de verse acompañado por una mujer así, Juan Manuel, despojándola de los valores cristianos y de las atribuciones de género, la presenta en el ejemplo XXVII como un vasallo y consejero leal que subyuga y pone su entendimiento al servicio de los intereses de su señor.

Recibido: $31 / 03 / 2020$

Aceptado: 20/05/2020

${ }^{71}$ Ibid., p. 125. 


\section{$\cos$}

LA INFLUENCIA de los CASTIGOS DEL REY DON SANCHO IV EN EL IDEAL FEMENINO DE JUAN MANUEL EN EL CONDE LUCANOR:

\section{ANÁLISIS DEL EJEMPLO XXVII}

RESUMEN: En este artículo se condensa el ideal femenino y matrimonial expuesto en los Castigos del rey don Sancho $I V$ y se analiza su presencia en el modelo de perfecta casada que Juan Manuel desarrolla en el ejemplo XXVII de El conde Lucanor. Según este ideal cristiano de influencia tomista, como criatura divina creada para ser compañera y auxiliar del hombre, posee entendimiento, inferior al del varón, y ha de ser, a semejanza de la Virgen María, una esposa virtuosa, activa y sumisa.

Palabras Clave: Castigos del rey don Sancho IV, Juan Manuel, El conde Lucanor, ejemplo XXVII, modelo femenino en la Edad Media.

THE INFLUENCE OF THE CASTIGOS DEL REY DON SANCHO IV ON THE FEMININE IDEAL OF JUAN MANUEL IN EL CONDE LUCANOR: ANALYSIS OF EXAMPLE 27

ABSTRACT: In this paper, the feminine and marital ideal exposed in the Castigos del rey don Sancho $I V$ is condensed and its presence is analyzed in the model of perfect wife and of the marital relations that Juan Manuel develops in the example 27 of El conde Lucanor. According to this Christian ideal of Thomistic influence, as a divine creature made to be a companion and auxiliary to man, she possesses an understanding inferior to that of a man, and she must be, like the Virgin Mary, a virtuous, active and submissive wife.

Keywords: Castigos del rey don Sancho IV, Juan Manuel, El conde Lucanor, Example 27, female model in Middle Ages. 